\title{
Appropriate household water treatment methods in Ethiopia: household use and associated factors based on 2005, 2011, and 2016 EDHS data
}

Abraham Geremew ${ }^{1 *} \mathbb{D}$, Bezatu Mengistie ${ }^{2}$, Jonathan Mellor ${ }^{3}$, Daniele Susan Lantagne ${ }^{4}$ Esayas Alemayehu ${ }^{5}$ and Geremew Sahilu'

\begin{abstract}
Background: Diarrheal disease attributable to water and sanitation can be prevented using point-of-use water treatment. In Ethiopia, a small number of households treat water at point-of-use with appropriate methods. However, evidence on factors associated with household use of these treatment methods is scarce. Therefore, this study is intended to explore the household use of appropriate point-of-use water treatment and associated factors in Ethiopia.
\end{abstract}

Methods: The data of 2005, 2011, and 2016 Ethiopian demographic and health surveys were used for analysis. Households reportedly treating water with bleach, boiling, filtration, and solar disinfection in each survey are considered as treating with appropriate treatment methods. Household water treatment with these treatment methods and factors associated was assessed using bivariate and multivariable regression. In addition, a region level difference in the treatment use was assessed by using multilevel modeling.

Results: The number of households that reported treating water with appropriate water treatment methods was 3.0\%, $8.2 \%$, and $6.5 \%$ respectively in 2005,2011 , and 2016 . Household heads with higher education had $5.99(95 \% \mathrm{Cl}=3.48$, 10.33), $3.61(95 \% \mathrm{Cl}=2.56,5.07)$, and $3.43(95 \% \mathrm{Cl}=2.19,6.37)$ times higher odds of using the treatment methods respectively in 2005, 2011, and 2016 compared to household heads who had no education. There was a significantly high number of households that used appropriate water treatment methods in 2011 ( $\mathrm{AOR}=2.78,95 \% \mathrm{Cl}=2.16,3.57$ ) and 2016 (AOR $=2.18,95 \% \mathrm{Cl}=1.64,3.89)$ compared to 2005 data. In pooled data analysis, the reported use of the treatment methods is associated with household head education, residency, drinking water sources, and owning radio and television. From a multilevel modeling, within-region variation is higher than between-region variations in the use of treatment methods in each survey.

Conclusions: Below $10 \%$ of households reportedly treating water at point-of-use in each survey attributable to different factors. Designing intervention strategies for wide-scale use of treatment methods at the country level is fundamental.

Keywords: Education of household head, Household use, Water treatment, Wealth status

\footnotetext{
* Correspondence: abrahamgeremew2010@gmail.com

'Ethiopian Institute of Water Resources, Addis Ababa University, Addis Ababa,

Ethiopia

Full list of author information is available at the end of the article
}

(c) The Author(s). 2018 Open Access This article is distributed under the terms of the Creative Commons Attribution 4.0 International License (http://creativecommons.org/licenses/by/4.0/) which permits unrestricted use, distribution, and reproduction in any medium, provided you give appropriate credit to the original author(s) and the source, provide a link to the Creative Commons license, and indicate if changes were made. The Creative Commons Public Domain Dedication waiver (http://creativecommons.org/publicdomain/zero/1.0/) applies to the data made available in this article, unless otherwise stated. 


\section{Background}

Diarrhea is among the leading cause of mortality and morbidity in developing countries [1]. The recent estimate shows that it is the fourth leading cause of death globally in children under 5 years, with $38 \%$ of all deaths [2]. Death from diarrheal disease in developing countries is mostly attributable to inadequate water, sanitation, and hygiene [3]. Various preceding systematic review findings suggest that point-of-use water treatment is one of the methods that can reduce this burden [4-6]. However, household adoption and sustained use are challenges [6]. A systematic review of household adoption and use of water, sanitation, and hygiene technologies categorizes the factors into three broad categories: psychosocial, contextual, and technology-related factors [7].

In Ethiopia, there are different point-of-use water treatment options being practiced of which boiling, adding bleach, filtration, and solar disinfection are listed as appropriate point-of-use water treatment methods [8, 9]. There has been an effort to improve the coverage of these water treatment options in the country [10]. The Health Transformation Plan of the country (2016-2020) shows that it is targeted to reach $35 \%$ coverage in the household use of water treatment methods and safe storage practices by 2020 [11]. However, the use of point-of-use water treatment methods is still low in Ethiopia $[8,9]$. Moreover, there is reporting on the number of households using these water treatments using the demographic and health surveys conducted every 5 years in the country. But advanced analysis of the data to show factors associated with households use of these treatment methods and the region level differences in the use of treatment has not yet been conducted for evidence-based intervention. Therefore, the current study is intended to assess the household use of appropriate point-of-use water treatment methods and associated factors, and region level differences in the treatment use using the three demographic and health surveys. The findings from this study can be used by concerned bodies to design a strategy for a wide-scale use of treatment methods for the ultimate health gain of reducing the burden of diarrheal disease in the country. In addition, the finding can be a basis for further study.

In the current analysis, it is hypothesized that the reported use of appropriate treatment methods is high in the households of educated household heads, high wealth quintiles, urban dwelling, owned a radio, owned a television, dependent on unimproved water sources, having under 5-year-old children, and male household head.

\section{Methods}

\section{Date source}

The Ethiopian Demographic and Health Survey (EDHS) conducted in 2005, 2011, and 2016 were used as a data source for analysis. The surveys were conducted based on a nationally representative sample households that provide estimates at the national and regional levels. Women of child-bearing age 15-49 and all men aged 15-59 in randomly selected households across the country were the target groups for the surveys $[8,9,12]$. This study considered all households in the country in each survey as a targeted population as it was intended to generalize the point-of-use water treatment practices at the national level. Data collection was taken place by interviewing respondents from the selected households $[8,9,12]$. The Federal Ministry of Health supported the survey implemented by the Central Statistical Agency with technical assistance from the ICF International through its MEASURE DHS project. MEASURE DHS is a 5-year project to assist institutions in collecting and analyzing data needed to plan, monitor, and evaluate population, health, and nutrition programs [13].

\section{Sample size and sampling technique}

The sample in each EDHS was designed to provide population and health indicators at the national and regional levels. The sample design allowed for specific indicators to be calculated for each of Ethiopia's 11 administrative regions: 9 regional states (Tigray, Afar, Amhara, Oromiya, Somali, Benishangul-Gumuz, Southern Nations Nationalities and Peoples (SNNP), Gambela, and Harari) and 2 city administrations (Addis Ababa and Dire Dawa). Accordingly, 14,500 households from 540 clusters in 2005 EDHS; 17,817 households from 624 clusters in 2011 EDHS, and 16,650 households from 645 clusters in 2016 EDHS were selected for the surveys. In each survey, each of the regions was stratified into urban and rural areas, and samples of enumeration areas (EAs) were selected independently in each stratum. The samples were selected using a stratified, two-stage cluster design. First, clusters were selected from the list of enumeration areas from the population and housing census sample frame (1994 census for 2005 EDHS and 2007 census for 2011 and 2016 EDHS). Second, households were selected after listing of households in all of the selected EAs for sampling frame. The detail of the sampling technique is found elsewhere $[8,9,12]$.

\section{Study variables}

Households reported using appropriate water treatment methods were considered for analysis as an outcome of an interest. According to 2011 and 2016 EDHS reports, adding bleach, boiling, filtration, and solar disinfection (SODIS) were taken as using appropriate water treatment methods. Therefore, households' reported use of boiling, adding bleach, filtering, or solar disinfecting took a binary form such that the use was considered a yes $(1=$ if the household had used either of the methods 
during each survey) and no otherwise $(0=$ if the household had used neither during each survey). The predictor variables are residency of households (categorized into urban and rural), household wealth status categorized into five quintiles (poorest, poorer, middle, higher, and highest), presence of under 5-year-old child in the household, education status of household head, owning television and radio, type of water sources (improved versus unimproved), sex of household head, age of household head, and intermittent water supply.

\section{Data analysis}

The "svy" command in Stata was used to weight the survey data for the adjustment of cluster sampling design. The weighted data were analyzed using descriptive (frequency and proportion), bivariate, and multivariable regression analysis. Bivariate regression was applied to determine unadjusted effects of each of the variables on household use of the treatment methods during each survey. Then, we subsequently included the variables with a $p$ value $<0.25$ for multivariable regression to assess the independent effect after controlling other variables [14]. In addition, a two-level multilevel modeling was employed to determine whether the effect of identified predictors vary due to regions. The two-level multilevel logistic regression that considers a collection of groups (regions) and within-group (random households selected within regions) is used for analysis because data from a random sample of level 1 households were collected from level 2 regions. For all analysis, the significant association of predictor variables was considered at $p$ value $<0.05$. All statistical analyses were conducted using Stata version 14.0 (Stata Corp, College Station, TX, USA). Multi-collinearity diagnostics were conducted to exclude the variable/s with the variance inflation

Table 1 The characteristics of the households in the DHS of 2005, 2011, and 2016, Ethiopia

\begin{tabular}{|c|c|c|c|c|}
\hline Household characteristics & & EDHS 2005, n (\%) & EDHS 2011, n (\%) & EDHS 2016, $n$ (\%) \\
\hline \multirow[t]{4}{*}{ Education status of head } & No education & $9236(67.5)$ & $9526(57.2)$ & $9083(54.7)$ \\
\hline & Primary & $2943(21.5)$ & $5325(32.0)$ & $5028(30.3)$ \\
\hline & Secondary & $1214(8.9)$ & $896(5.4)$ & $1324(8.0)$ \\
\hline & Higher & $287(2.1)$ & $910(5.5)$ & $1168(7.0)$ \\
\hline \multirow[t]{5}{*}{ Wealth status } & Poorest & $2754(20.1)$ & $3208(19.2)$ & $3202(19.2)$ \\
\hline & Poorer & $2838(20.7)$ & 3219 (19.3) & $3203(19.2)$ \\
\hline & Middle & 2668 (19.5) & 3091 (18.5) & $3121(18.8)$ \\
\hline & Higher & $2529(18.4)$ & 3067 (18.4) & $3084(18.5)$ \\
\hline & Highest & $2923(21.3)$ & $4102(24.6)$ & $4040(34.3)$ \\
\hline \multirow[t]{2}{*}{ Sex of household head } & Male & 10,594(77.3) & $12,335(73.9)$ & $12,426(74.6)$ \\
\hline & Female & $3117(22.7)$ & $4352(26.1)$ & $4224(25.4)$ \\
\hline \multirow[t]{5}{*}{ Person fetching water } & Adult woman & 10,209 (81.4) & $10,404(71.3)$ & $9612(72.2)$ \\
\hline & Adult man & $806(6.4)$ & $1277(8.8)$ & $1193(9.0)$ \\
\hline & Female below 15 years old & $1113(8.9)$ & $2065(14.1)$ & $1726(13.0)$ \\
\hline & Male below 15 years old & $329(2.6)$ & 701 (4.8) & $576(4.3)$ \\
\hline & Other & $85(0.7)$ & $154(1.0)$ & $204(1.5)$ \\
\hline \multirow[t]{2}{*}{ Radio ownership } & No & $9090(66.3)$ & $9917(59.4)$ & $11,952(71.8)$ \\
\hline & Yes & $4617(33.7)$ & $6767(40.6)$ & $4698(28.2)$ \\
\hline \multirow[t]{2}{*}{ Television ownership } & No & $13,039(95.1)$ & $14,947(89.6)$ & $14,354(86.2)$ \\
\hline & Yes & $668(4.9)$ & $1730(10.4)$ & 2296 (13.8) \\
\hline \multirow[t]{2}{*}{ Residency } & Rural & $11,741(85.6)$ & $12,915(77.4)$ & $13,266(79.7)$ \\
\hline & Urban & $1970(14.4)$ & $3772(22.6)$ & $3384(20.3)$ \\
\hline \multirow[t]{2}{*}{ Water sources } & Unimproved sources & 8185 (59.7) & $7730(46.3)$ & $5857(35.2)$ \\
\hline & Improved sources & $5526(40.3)$ & $8957(53.7)$ & $10,793(64.8)$ \\
\hline \multirow[t]{3}{*}{ Distance of water sources } & Water on premises & $1147(8.4)$ & $2075(12.4)$ & $3339(20.1)$ \\
\hline & $<30$ min (round trip) & $6076(44.3)$ & $5774(34.6)$ & $5871(35.3)$ \\
\hline & $\geq 30$ min (round trip) & $6489(47.3)$ & $8838(53.0)$ & $7440(44.7)$ \\
\hline
\end{tabular}

Households with unknown response to the water distance were categorized into $>30$ min in all three surveys; therefore, column total may not be equal to national reports 
factor (VIF) of greater than 10 from multivariable regression.

\section{Results}

Household characteristics and drinking water sources

Data about appropriate water treatment and characteristics attributable to it were analyzed using 13,711, 16,672, and 16,650 households respectively for 2005,2011 , and 2016 EDHS. Table 1 shows the household characteristics of the three surveys. Of total household heads, about $68 \%$ in $2005,57 \%$ in 2011, and 55\% in 2016 had no formal education. A small number of households (4.9\%) owned a television in the 2005 survey, and the number increased to $13.8 \%$ in 2016 survey. More than $70 \%$ of adult women were responsible to fetch water in each of the surveys. There was an increasing trend in the number of households using improved water sources in three surveys. The number of households accessed the water on the premises was $8.4 \%$ in 2005 and increased to $20.1 \%$ in the 2016 survey. The number of households that accessed drinking water supplies within $30 \mathrm{~min}$ in 2011 and 2016 surveys was almost the same.

\section{Household reported the use of water treatment methods}

The number of households treating their water prior to drinking with any treatment options was $8.0 \%$ in 2005 , $10.2 \%$ in 2011, and 9.4\% in 2016 (Table 2). In 2005 EDHS data, a total of $3.0 \%$ of households had used one of the appropriate treatment methods. Explicitly, 2.4\% of households had reportedly used boiling, $0.2 \%$ of households had reportedly used bleach, and $0.3 \%$ of households had reportedly used a filter as point-of-use water treatment methods. In 2011, the number of households that reportedly used boiling, bleach, and filter as household water treatment methods was $2.7 \%, 5.8 \%$, and $0.2 \%$, respectively. In this survey, there was no household that reportedly used SODIS. The total number of households that reportedly used the appropriate household water treatment methods in 2011 was $8.2 \%$. In 2016, 6.5\% of households had reportedly used either of the listed treatment methods to treat their drinking water prior to drinking. Specifically, $2.2 \%, 3.4 \%, 1.1 \%$, and $0.1 \%$ was the number of households that reportedly used boiling, bleach, filter, and SODIS, respectively, as a household water treatment method. In general, appropriate water treatment use is least in the 2005 survey and highest in 2011 survey.

\section{Result of bivariate and multivariable analysis}

Table 3 indicates the bivariate regression of the household use of appropriate point-of-use water treatment methods in the three surveys. In the bivariate regression analysis, the socio-demographic and economic characteristics of households were associated with the use of appropriate point-of-use water treatment methods. The odds of using appropriate point-of-use water treatment methods in urban area are $1.51(95 \% \mathrm{CI}=1.03,2.22)$ times higher in $2005,1.80(95 \% \mathrm{CI}=1.32,2.45)$ times higher in 2011, and $1.58(95 \% \mathrm{CI}=1.17,2.13)$ times higher in 2016 compared to rural area. Household head with higher education had the odds of $7.42(95 \% \mathrm{CI}=$ $4.78,11.52)$ times higher in $2005,6.65(95 \% \mathrm{CI}=4.61$, 9.58) times higher in 2011, and $3.27(95 \% \mathrm{CI}=2.29$, 4.67) times higher in the reported use of appropriate water treatment methods compared to house head who had no education. The odds of reported use of appropriate treatment methods among households found in the highest wealth quintile in 2005, 2011, and 2016 were $2.77(95 \% \mathrm{CI}=1.39,5.54), 5.02(95 \% \mathrm{CI}=3.19,7.90)$, and $1.83(95 \% \mathrm{CI}=1.06,3.18)$ times higher, respectively, than households found in poorest wealth quintile.

Table 4 shows multivariable regression analysis on the use of appropriate point-of-use water treatment methods and associated factors. There was no collinearity among

Table 2 Type of water treatment methods used by households in DHS of 2005, 2011, and 2016, Ethiopia

\begin{tabular}{|c|c|c|c|c|}
\hline \multirow[t]{2}{*}{ Treatment type } & & \multicolumn{3}{|l|}{ Household use in survey year } \\
\hline & & 2005, weighted frequency (\%) & 2011, weighted frequency (\%) & 2016, weighted frequency (\%) \\
\hline \multirow[t]{8}{*}{ All treatment methods } & Boiling & $335(2.4)$ & $450(2.7)$ & $364(2.2)$ \\
\hline & Bleach & $32(0.2)$ & $973(5.8)$ & $567(3.4)$ \\
\hline & Cloth straining & $626(4.6)$ & $206(1.2)$ & $331(2.0)$ \\
\hline & Filtration & $47(0.3)$ & $40(0.2)$ & $182(1.1)$ \\
\hline & SODIS & 0 & 0 & $11(0.1)$ \\
\hline & Let it stand and settle & $21(0.2)$ & $21(0.1)$ & $59(0.4)$ \\
\hline & Other & $42(0.3)$ & $35(0.2)$ & $28(0.2)$ \\
\hline & Total & $1103(8.0)$ & $1725(10.2)$ & $1542(9.4)$ \\
\hline \multicolumn{2}{|c|}{$\begin{array}{l}\text { Appropriate treatment methods (boiling, adding leach, } \\
\text { filtration, or SODIS) }\end{array}$} & $409(3.0)$ & $1368(8.2)$ & $1081(6.5)$ \\
\hline
\end{tabular}

filtration, or SODIS)

SODIS $=0$ is due to the weighting of data; number of households using appropriate treatment methods is obtained by weighting the sum of the number of households reportedly using boiling, bleach, filter, and SODIS 


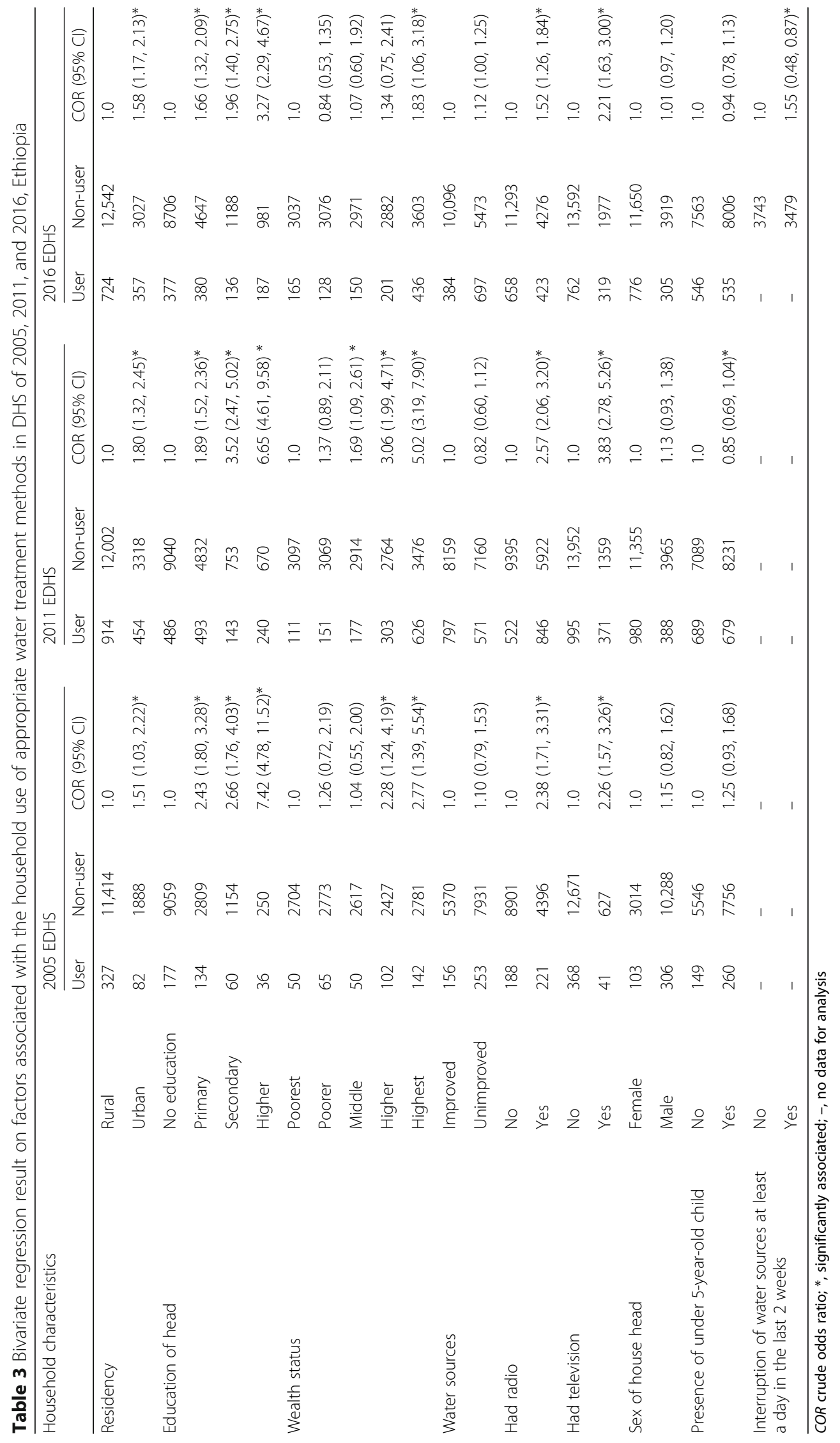




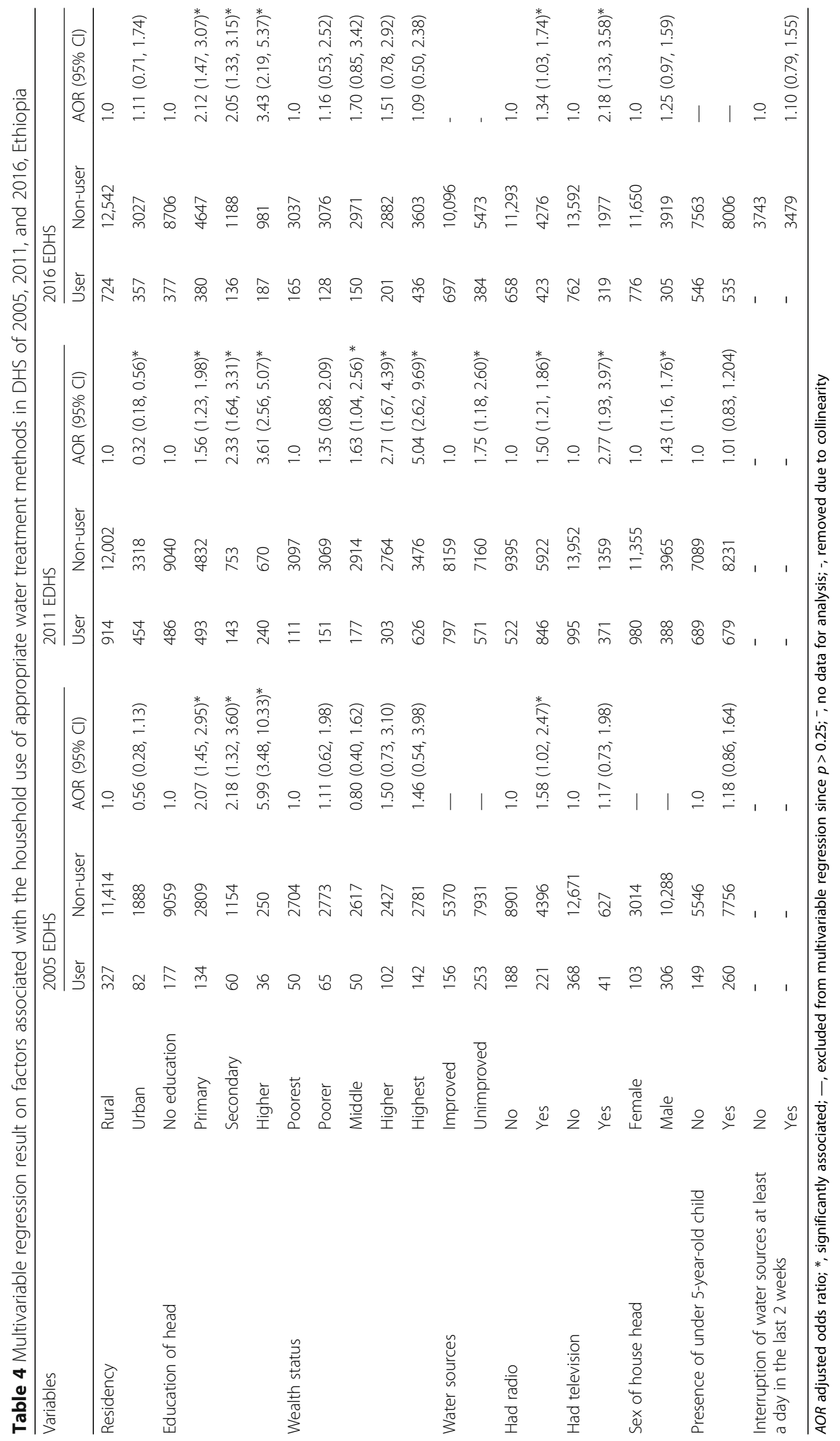


predictor variables as the multi-collinearity diagnostics did not show variables with VIF of greater than 10. In all surveys, education status of household head and owning radio had a significant association with the household use of the water treatment methods after controlling other variables. The household head with higher education in 2005, 2011, and 2016 had 5.99 (95\% CI $=3.48$, $10.33), 3.61(95 \% \mathrm{CI}=2.56,5.07)$ and $3.43(95 \% \mathrm{CI}=$ $2.19,5.37)$ times higher odds ratio, respectively, to use appropriate treatment methods as compared to household head who had no education. Households owned a radio in 2005,2011 , and 2016 had $1.58(95 \% \mathrm{CI}=1.02$, 2.47), $1.50(95 \% \mathrm{CI}=1.21,1.86)$, and $1.34(95 \% \mathrm{CI}=1.03$, 1.74) times higher odds ratio, respectively, to use the appropriate water treatment methods as compared to the households who did not own radio. There is sufficient evidence to accept the hypothesis that the reported use of appropriate treatment methods is high in the households of educated household heads and owned a radio in all the three surveys. But, we fail to accept the hypothesis that there is a high reported use of the treatment methods in the households located in urban areas, found in high wealth quintiles, owning a television, dependent on unimproved water sources, and having children with age below 5 years in 2005 EDHS surveys. From the pooled data regression, the odds of treating water with an appropriate water treatment were 2.78 $(95 \% \mathrm{CI}=2.16,3.57)$ and $2.18(1.64,2.89)$ times higher in 2011 and 2016, respectively, compared to 2005 DHS survey. Households with primary, secondary, and higher education head had 1.71 (1.44, 2.02), 2.17 (1.73, 2.73), and $3.58(2.79,4.59)$ times higher odds to use appropriate water treatment methods, respectively, as compared to household heads with no education. Moreover, the odds of treating water with appropriate household treatment methods is higher in the households of being in higher and highest wealth quintiles, being living in rural, dependent in unimproved water sources, and owning radio and television (Table 5). In a pooled data analysis, there are sufficient evidences to accept the hypothesis

Table 5 Multivariable regression result of a pooled data of three DHS on factors associated with the household use of appropriate water treatment, Ethiopia

\begin{tabular}{|c|c|c|c|c|}
\hline \multirow[t]{2}{*}{ Variables } & & \multicolumn{2}{|c|}{ Appropriate treatment use, weighted frequency } & \multirow[t]{2}{*}{ AOR (95\% Cl) } \\
\hline & & User & Non-user & \\
\hline \multirow[t]{3}{*}{ Survey year } & 2005 & 409 & 13,302 & 1.0 \\
\hline & 2011 & 1368 & 15,319 & $2.78(2.16,3.57)^{*}$ \\
\hline & 2016 & 1081 & 15,569 & $2.18(1.64,3.89)^{*}$ \\
\hline \multirow[t]{2}{*}{ Residency } & Rural & 1965 & 35,957 & 1.0 \\
\hline & Urban & 893 & 8233 & $0.49(0.33,0.72)^{*}$ \\
\hline \multirow[t]{4}{*}{ Education of head } & No education & 1040 & 26,805 & 1.0 \\
\hline & Primary & 1006 & 12,289 & $1.71(1.44,2.02)^{*}$ \\
\hline & Secondary & 339 & 3094 & $2.17(1.73,2.73)^{*}$ \\
\hline & Higher & 463 & 1901 & $3.56(2.77,4.58)^{*}$ \\
\hline \multirow[t]{5}{*}{ Wealth status } & Poorest & 326 & 8839 & 1.0 \\
\hline & Poorer & 343 & 8918 & $1.03(0.72,1.46)$ \\
\hline & Middle & 377 & 8502 & $1.16(0.77,1.75)$ \\
\hline & Higher & 607 & 8072 & $1.78(1.18,2.67)^{*}$ \\
\hline & Highest & 1204 & 9860 & $2.47(1.53,4.00)^{*}$ \\
\hline \multirow[t]{2}{*}{ Water sources } & Improved & 1650 & 23,626 & 1.0 \\
\hline & Unimproved & 1208 & 20,565 & $1.76(1.39,2.22)^{*}$ \\
\hline \multirow[t]{2}{*}{ Had radio } & No & 1369 & 29,590 & 1.0 \\
\hline & Yes & 1489 & 14,593 & $1.41(1.22,1.62)^{*}$ \\
\hline \multirow[t]{2}{*}{ Had television } & No & 2126 & 40,214 & 1.0 \\
\hline & Yes & 731 & 3963 & $2.25(1.72,2.95)^{*}$ \\
\hline \multirow[t]{2}{*}{ Sex of house head } & Female & 796 & 10,898 & 1.0 \\
\hline & Male & 2063 & 33,293 & $1.28(1.28,1.68)^{*}$ \\
\hline \multirow[t]{2}{*}{ Presence of under 5-year-old child } & No & 1384 & 20,197 & 1.0 \\
\hline & Yes & 1474 & 23,993 & $1.01(0.89,1.16)$ \\
\hline
\end{tabular}


that the reported use of appropriate treatment methods is high in the households of living in rural, educated household heads, found in high wealth quintiles, owned a radio, owned a television, and dependent on unimproved water sources.

\section{Results of multilevel modeling}

The data had a two-level hierarchical structure with households at level 1 nested within 11 regions at level 2 . We began by the empty (intercept only) two-level model for a dichotomous outcome variable (household use or non-use appropriate treatment methods). The output shows that there was a variation in the use of appropriate water treatment due to the variation in regions. The interclass correlation from empty model indicates that $15.3 \%$ of variations in $2005,9.1 \%$ of the variation in 2011, and $29.6 \%$ of variations in 2016 are attributable to the difference in the region (Table 6). The variations in the use of treatment methods due to the difference in the region were significant in each survey regardless of whether there was a higher within-region variation compared to between-regions variation. The higher within-region variation than between-regions variations suggests that the use of point-of-use water treatment methods is a nationwide problem.

Similar to the output of multivariable regression analysis, the fixed part of multilevel modeling indicates that household use of appropriate water treatment options generally was associated with the educational status of household head, wealth status, and ownership of radio and television. The 2016 survey shows that supplying water intermittently to household had $1.26(95 \% \mathrm{CI}=1.06,1.49)$ times higher odds of using treatment methods regardless of the region where the households are located (result not indicated in the table). In 2005 and 2011 EDHS, households dependent on unimproved water sources were $34 \%$ and $37 \%$ more likely to use water treatment methods, respectively, compared to households using improved water sources. In 2016, households' use of either boiling, filtration, bleach, and SODIS was associated with the presence of under 5 -year-old children in the household (AOR 1.12; 95\% $\mathrm{CI}=0.99,1.27)$ (Table 7).

\section{Discussion}

Primary prevention of the diseases consists of manipulation of human environment that includes water supply [15]. Treating water prior to drinking, which can be taken as a primary prevention method for diarrhea, is found to be effective in reducing the disease [4-6]. In Ethiopia, despite having preceding studies that show the effectiveness of point-of-use water treatment in reducing diarrhea [16, 17], it is still among the common health problems [18-20]. Reducing the problem using household water treatment can be ensured when the treatment methods are adopted and effectively and consistently used [21, 22]. To ensure the wide-scale and effective use of household water treatment methods, identifying and intervening the factors affecting the use is indispensable. The current study focused on the household reported use of appropriate household water treatment methods and the factors associated with the use for future intervention.

The analysis of the three EDHS data indicates that there is an increasing trend in the number of households that used water from improved sources. At the same time, the number of households treating water with different point-of-use water treatment methods has increased from 2005 to 2016. Particular to appropriate water treatment use, $3.0 \%, 8.2 \%$, and $6.5 \%$ of households had reportedly used the treatment options respectively in 2005, 2011, and 2016 EDHS.

Household point-of-use water treatment was associated with ownership of radio and television that might be because of conveying of information about the health benefits of treating water and health risk of untreated water by these media. In this regard, a study finding shows that conveying relevant information about household water quality improves the adoption of protective behaviors and technologies [23].

Households in higher and highest wealth quintile had higher odds of using either of the treatment options in the 2005 and 2011 surveys. Similar to our finding, an assessment in Egypt shows that households in the wealthiest quintile were 18.2 times more likely to use filters than those in the remaining four wealth quintiles [24].

The result also indicates that households dependent on unimproved water sources were more likely to use either of the treatment options in the survey of 2011. Our

Table 6 Intercept only model on household use of appropriate water treatment methods DHS 2005, 2011, and 2016, Ethiopia

\begin{tabular}{llll}
\hline Use of treatment & \multicolumn{3}{l}{ Empty model $(95 \% \mathrm{Cl})$} \\
\cline { 2 - 3 } & 2005 & 2011 & 2016 \\
\hline Level 1 (the odds of treatment use in an average regions) & $0.02(0.01,0.03)$ & $0.11(0.08,0.15)$ & $0.23(0.20,0.26)$ \\
Level 2 (the variance of random factor or odds of treatment use between regions) & $0.59(0.24,1.49)$ & $0.33(0.14,0.77)$ & $1.13(0.56,3.43)$ \\
Interclass correlation in percent & $15.3(6.70,31.13)$ & $9.1(4.06,19.06)$ & $29.6(14.5,51.03)$
\end{tabular}


Table 7 Full multilevel model on household use of appropriate water treatment methods in DHS 2005, 2011, and 2016, Ethiopia

\begin{tabular}{|c|c|c|c|c|c|}
\hline & \multirow[t]{2}{*}{ Variables } & & \multicolumn{3}{|l|}{ OR $(95 \% \mathrm{Cl})$} \\
\hline & & & 2005 & 2011 & 2016 \\
\hline \multirow[t]{21}{*}{ Fixed part } & \multirow[t]{2}{*}{ Residency } & Rural & 1 & 1 & 1 \\
\hline & & Urban & $0.86(0.56,1.33)$ & $0.56(0.46,0.68)^{*}$ & $0.90(0.70,1.16)$ \\
\hline & \multirow[t]{4}{*}{ Education of head } & No education & 1 & 1 & 1 \\
\hline & & Primary & $1.67(1.24,2.26)^{*}$ & $1.47(1.28,1.69)^{*}$ & $1.84(1.58,2.15)^{*}$ \\
\hline & & Secondary & $2.32(1.64,3.26)^{*}$ & $2.19(1.80,2.65)^{*}$ & $2.15(1.76,2.62)^{*}$ \\
\hline & & Higher & $5.51(3.63,8.35)^{*}$ & $2.96(2.45,3.57)^{*}$ & $3.01(2.47,3.66)^{*}$ \\
\hline & \multirow[t]{5}{*}{ Wealth status } & Poorest & 1 & 1 & 1 \\
\hline & & Poorer & $1.36(0.82,2.25)$ & $1.62(1.26,2.09)^{*}$ & $0.90(0.69,1.16)$ \\
\hline & & Middle & $1.47(0.88,2.46)$ & $1.85(1.43,2.39)^{*}$ & $1.16(0.90,1.50)$ \\
\hline & & Higher & $2.24(1.37,3.68)^{*}$ & $2.99(2.36,3.78) *$ & $1.49(1.16,1.90)^{*}$ \\
\hline & & Highest & $2.447(1.41,4.34)^{*}$ & $5.24(3.99,6.88) *$ & $1.55(1.14,2.11)^{*}$ \\
\hline & \multirow[t]{2}{*}{ Water sources } & Unimproved & 1 & 1 & \\
\hline & & Improved & $0.66(0.48,0.91)^{*}$ & $0.63(0.54,0.72) *$ & $0.51(0.44,0.60)^{*}$ \\
\hline & \multirow[t]{2}{*}{ Radio ownership } & No & 1 & 1 & 1 \\
\hline & & Yes & $1.39(1.03,1.87)^{*}$ & $1.48(1.31,1.67) *$ & $1.21(1.07,1.38)^{*}$ \\
\hline & \multirow[t]{2}{*}{ Television ownership } & No & 1 & 1 & 1 \\
\hline & & Yes & $1.52(1.08,2.15)^{*}$ & $1.87(1.59,2.19) *$ & $1.89(1.55,2.30)^{*}$ \\
\hline & \multirow[t]{2}{*}{ Sex of house head } & Female & 1 & 1 & 1 \\
\hline & & Male & $1.50(1.17,1.93)^{*}$ & $1.30(1.15,1.47) *$ & $1.24(1.09,1.41)^{*}$ \\
\hline & \multirow[t]{2}{*}{ Presence of under 5-year-old child } & No & 1 & 1 & 1 \\
\hline & & Yes & $1.02(0.81,1.28)$ & $1.06(0.95,1.19)$ & $1.07(0.95,1.20)^{*}$ \\
\hline \multicolumn{3}{|c|}{ Random part (region-level variation) } & $0.39(0.14,1.07)$ & $0.17(0.07,0.41)$ & $0.11(0.04,0.27)$ \\
\hline
\end{tabular}

The data used for multilevel modeling were not weighted data, The result of multilevel modeling with the inclusion of intermittent water supply was run independently since it was collinear with water sources; $O R$ odds ratio; *, significantly associated

finding complies with a study finding in Zambia that shows that households obtaining water from unimproved sources (rivers and streams) were more likely to chlorinate their water [25]. Another study finding shows that households that considered public water was unsafe for drinking preferred to boil their drinking water prior to consumption [26]. On the other hand, the finding on households dependent on improved water sources was less likely to use treatment methods might be from the households' perception that improved water is free of pathogens, and post-collection contamination is less likely even if further study is needed in this regard. But, it is arguable that the treatment methods should not only be used by households dependent on unimproved water sources in the country due to the prior report that shows that about $32 \%$ of improved water sources do not meet the national standards of microbial load per $100 \mathrm{ml}$ [27].

Moreover, the 2016 survey analysis on households with an intermittent water supply had higher odds of treating their water at the household level is corroborated by a study finding in Egypt that shows households with an intermittent supply were more likely to let the water stand and settle [24].

Household head with at least primary education level had higher odds of treating their water prior to drinking than households heads who had no formal education in each of the three surveys. Our finding is similar to a study finding in Zambia that indicates that chlorine use was more likely among those with post-secondary education [25].

The number of households treating water at pointof-use in 2005 was significantly lower than the two latter surveys. There was an increasing trend from 2005 to 2011 in the number of households using appropriate water treatment methods. The rise in the number of households reportedly using the treatment methods from 2005 to 2011 might be from the emphasis given to demand creation service during this survey time and its persuasiveness. There was a decreasing trend from 2011 to 2016 in the number of households reportedly treating their water decreased. The number of households dependent on improved water sources increased from 2011 to 2016. Therefore, decreasing in the number of 
households using point-of-use water treatment from 2011 to 2016 might be from the perception of the households to treat improved water sources, less emphasis might be given to promotion services and shortage in the supply of the treatment methods. The declining number of users from 2011 to 2016 also shows limitations in the government effort to scale-up of different treatment methods and disagree with the prior reports $[10,28]$. Moreover, it is suspicious that the report on the cooperation of concerned government offices with different organizations that pledge support in facilitating partnerships and effective implementation of HWTS [10].

In the country, since 2003, health extension workers have been deployed and implementing water safety measures including the household water treatment and safe storage practices [29]. The current finding that shows more than $90 \%$ of households that do not use any of point-of-use water treatment methods suggests the existence of either a little emphasis or gap in the implementation of the package. In addition, a decreasing trend from 2011 to 2016 contradicts the national plan targeted to reach $35 \%$ coverage of household water treatment use and safe storage practices at the end of 2020 [11].

\section{Strengths and limitations}

The EDHS data we analyzed were collected cross-sectionally and, therefore, have the following limitations: (1) The responses were liable to biases (social desirability bias); (2) The analysis fails to show the cause and effect relationship between independent variables and dependent variable [30]. The data did not indicate whether households claimed using the treatment methods were confirmed users and how consistent is the water treatment. In addition, the data did not explicitly indicate different types of filtration methods used by households. Psychosocial factors, one of the factors associated with WASH technology adoption and use, were not included in the data for analysis. The Ethiopia Demographic and Health Survey is conducted in every 5 years via appropriate procedures of selecting households that would represent the whole population in the country. Therefore, the representativeness of the data is one of the strengths when compared with area-specific studies being conducted in the country.

\section{Conclusions}

Below $10 \%$ of households had treated their water at point-of-use via appropriated treatment methods during all the three Ethiopian Demographic and Health Surveys. Household and individual level characteristics mainly education status of household head, owning a radio and television, and wealth quintiles had an association with the household use of the treatment methods. Community-level factors mainly being in urban or rural had also a significant association with treatment use in the 2011 survey. There were within-region and between-region variations in the use of treatment methods in each survey. The finding in general suggests the need for designing intervention and implementation strategies at the national level for wide-scale use of the treatment methods which ultimately ensure the health gains. A study on the consistency in the use of the treatment methods among reported users and its effectiveness against diarrheal disease needs to be conducted in the country. Moreover, further study about household behavioral factors related to the safe water system is needed to design appropriate behavior changing intervention strategies.

\section{Abbreviations \\ AOR: Adjusted odds ratio; COR: Crude odds ratio; DHS: Demographic and Health Survey; EAs: Enumeration areas; EDHS: Ethiopian Demographic Health Survey; FMOH: Federal Ministry of Health; HWTS: Household water treatment system; ICF: International Classification of Functioning; MoWIE: Ministry of Water, Irrigation and Electricity; SNNPR: Southern Nation, Nationalities and People; SODIS: Solar disinfection; WASH: Water, sanitation, and hygiene}

\section{Acknowledgements}

The authors would like to thank MEASURE DHS for providing the dataset to conduct this study.

\section{Availability of data and materials \\ The data that support the findings of this study are available from MEASURE DHS but restrictions apply to the availability of these data, which were used under license for the current study, and so are not publicly available. Data are however available from the authors upon reasonable request and with permission from MEASURE DHS.}

\section{Authors' contributions}

AG conceived and designed the study, analyzed the data, and interpreted and drafted the manuscript. BM, JM, DSL, EA, and GS assisted with the analysis and interpretation of data and critically reviewed the manuscript. All authors have read and approved the final manuscript.

\section{Ethics approval and consent to participate}

The data were obtained via online registration to MEASURE DHS program and downloaded after the purpose of the analysis was communicated and approved. Initially, each of the surveys was conducted after ethical clearance was obtained from the National Research Ethic Review Committee (NRERC).

Consent for publication

Not applicable

Competing interests

The authors declare that they have no competing interest.

\section{Publisher's Note}

Springer Nature remains neutral with regard to jurisdictional claims in published maps and institutional affiliations.

\section{Author details}

${ }^{1}$ Ethiopian Institute of Water Resources, Addis Ababa University, Addis Ababa, Ethiopia. ${ }^{2}$ Department of Environmental Health Sciences, College of Health and Medical Sciences, Haramaya University, Dire Dawa, Ethiopia. ${ }^{3}$ Department of Civil and Environmental Engineering, University of Connecticut, Mansfield, USA. ${ }^{4}$ Department of Civil and Environmental Engineering, Tufts University, Medford, USA. ${ }^{5}$ Department of Civil and Environmental Engineering, Institute of Technology, Jimma University, Jimma, Ethiopia. 
Received: 8 May 2018 Accepted: 17 September 2018

Published online: 27 September 2018

\section{References}

1. Black RE, Cousens S, Johnson HL, Lawn JE, Rudan I, Bassani DG, Jha P, Campbell H, Walker CF, Cibulskis R. Global, regional, and national causes of child mortality in 2008: a systematic analysis. Lancet. 2010; 375(9730):1969-87.

2. Troeger C, Forouzanfar M, Rao PC, Khalil I, Brown A, Reiner RC Jr, Fullman N, Thompson RL, Abajobir A, Ahmed M. Estimates of global, regional, and national morbidity, mortality, and aetiologies of diarrhoeal diseases: a systematic analysis for the Global Burden of Disease Study 2015. Lancet Infect Dis. 2017:17(9):909-48.

3. Prüss-Ustün A, Bartram J, Clasen T, Colford JM, Cumming O, Curtis V, Bonjour S, Dangour AD, De France J, Fewtrell L. Burden of disease from inadequate water, sanitation and hygiene in low and middle income settings: a retrospective analysis of data from 145 countries. Trop Med Int Health. 2014;19(8):894-905.

4. Clasen T, Schmidt W-P, Rabie T, Roberts I, Cairncross S. Interventions to improve water quality for preventing diarrhoea: systematic review and meta-analysis. BMJ. 2007;334(7597):782.

5. Fewtrell L, Kaufmann RB, Kay D, Enanoria W, Haller L, Colford JM Jr. Water, sanitation, and hygiene interventions to reduce diarrhoea in less developed countries: a systematic review and meta-analysis. Lancet Infect Dis. 2005; 5(1):42-52.

6. Waddington $H$, Snilstveit $B$, White $H$, Fewtrell L. Water, sanitation and hygiene interventions to combat childhood diarrhoea in developing countries, vol. 31. India: International Initiative for Impact Evaluation New Delhi; 2009.

7. Dreibelbis R, Hulland K, McDonald L, Sultana F, Schwab K, Winch P. What factors affect sustained adoption of clean water and sanitation technologies? In: A Systematic Review of Literature Protocol. London: EPPICentre: Social Science Research Unit, Institute of Education, University of London; 2013.

8. Central Statistical Agency [Ethiopia] and ICF International: Ethiopia Demographic and Health Survey [https://dhsprogram.com/pubs/pdf/fr255/ fr255.pdf].

9. Central Statistical Agency [Ethiopia] and ICF International [https:// dhsprogram.com/pubs/pdf/FR328/FR328.pdf].

10. FMOH. Federal Minsitry of Health: national workshop on evaluating household water treatment performance and scaling up safe-drinking water solutions. Addis Ababa, Ethiopia: Federal Ministry of Health; 2013.

11. $\mathrm{FMOH}$. Federal Democratic Republic of Ethiopia, Federal Ministry of Health; Health Sector Transformation Plan (HSTP) 2015/16-2019/20. ETHIOPIA: Health FDRoEMo; 2015. p. 184.

12. CSA, ORC M. Demographic and Health Survey 2005. Addis Ababa, Ethiopia and Calverton, Maryland, USA: Central Statistical Agency and ORC Macro; 2006

13. ICF-International. Demographic and Health Survey sampling and household listing manual. Calverton, Maryland, USA: ICF International MEASURE DHS; 2012.

14. Mickey J, Greenland S. A study of the impact of confounder-selection criteria on effect estimation. Amer J Epidemiol. 1989:129:125-37.

15. Clarke E. What is preventive medicine? Can Fam Phys. 1974;20(11):65.

16. Mengistie B, Berhane $Y$, Worku A. Household water chlorination reduces incidence of diarrhea among under-five children in rural Ethiopia: a cluster randomized controlled trial. PLoS One. 2013;8(10):e77887.

17. Boisson S, Schmidt WP, Berhanu T, Gezahegn H, Clasen T. Randomized controlled trial in rural Ethiopia to assess a portable water treatment device. Environ Sci Technol. 2009;43(15):5934-9.

18. Anteneh ZA, Andargie $K$, Tarekegn M. Prevalence and determinants of acute diarrhea among children younger than five years old in Jabithennan District, Northwest Ethiopia, 2014. BMC Public Health. 2017;17(1):99.

19. Hashi A, Kumie A, Gasana J. Prevalence of diarrhoea and associated factors among under-five children in Jigjiga District, Somali Region, eastern Ethiopia. Open J Prev Med. 2016;6(10):233-46.

20. Mengistie B, Berhane $Y$, Worku A. Prevalence of diarrhea and associated risk factors among children under-five years of age in eastern Ethiopia: a crosssectional study. Open J Prev Med. 2013;3(07):446.

21. Brown J, Clasen T. High adherence is necessary to realize health gains from water quality interventions. PLoS One. 2012;7(5):e36735.
22. Enger KS, Nelson KL, Rose JB, Eisenberg JN. The joint effects of efficacy and compliance: a study of household water treatment effectiveness against childhood diarrhea. Water Res. 2013;47(3):1181-90.

23. Madajewicz M, Alexander $P$, Alexander $V$, Joseph G, Iftikhar $H$, Hasina $M$, Roksana S, Habibul A. Can information alone change behavior? Response to arsenic contamination of groundwater in Bangladesh. J Develop Econ. 2007; 84(2):731754.

24. Wright J, Gundry SW. Household characteristics associated with home water treatment: an analysis of the Egyptian Demographic and Health Survey. J Water Health. 2009;7(1):21-9.

25. Olembo L, Kaona F, Tuba M, Burnham G. Safe water systems: an evaluation of the Zambia CLORIN Program (final report). In. Zambia: Environmental Health Project; 2004

26. Francis MR, Nagarajan G, Sarkar R, Mohan VR, Kang G, Balraj V. Perception of drinking water safety and factors influencing acceptance and sustainability of a water quality intervention in rural southern India. BMC Public Health. 2015:15(1):731.

27. Tadesse D, Desta A, Geyid A, Girma W, Fisseha S, Schmoll O. Rapid assessment of drinking water quality in the Federal Democratic Republic of Ethiopia. Geneva: World Health Organization; 2010.

28. MoWIE. In: Directorate WSS, editor. Ministry of Water, Irrigation and Energy, Water Supply \& Sanitation Directorate: Manual For Accelerating Self Supply Program. Addis Ababa, Ethiopia: Ministry of Water, Irrigation and Energy; 2014. p. 104.

29. FMOH. Federal Ministry of Health, Ethiopia: guidelines for Health Extension Program. Ministry of Health: Addis Ababa, Ethiopia; 2007.

30. Carlson M, Morrison R. Study design, precision, and validity in observational studies. J Palliat Med. 2009;12(1):77-8.

\section{Ready to submit your research? Choose BMC and benefit from:}

- fast, convenient online submission

- thorough peer review by experienced researchers in your field

- rapid publication on acceptance

- support for research data, including large and complex data types

- gold Open Access which fosters wider collaboration and increased citations

- maximum visibility for your research: over $100 \mathrm{M}$ website views per year

At BMC, research is always in progress.

Learn more biomedcentral.com/submissions 